\section{Projeto Esperança/Cooesperança, Santa Maria, RS: o caso dos agricultores familiares associados}

Resumo: A busca de alternativas para a manutenção de famílias no campo é um tema que vem sendo fortemente trabalho na região central do estado do Rio Grande do Sul. O Projeto Esperança/Cooesperança é uma das entidades de destaque em relação ao tema na perspectiva da economia solidária. $O$ caso dos agricultores familiares associados ao Projeto Esperança/ Cooesperança, e sua relação com a economia solidária é o centro de interesse do presente trabalho, que objetiva compreender como as famílias de agricultores de Santa Maria, associados à Cooperativa desenvolvem suas atividades produtivas e como estas se inserem na perspectiva da economia solidária, suas relações com a produção e comercialização e suas condições de vida, são os pontos a serem analisados nesta pesquisa.

\section{Project Esperança/Cooesperança, Santa Maria, RS: the case of associated family farmers}

\footnotetext{
Abstract: The search for alternatives for the maintenance of rural families is a theme that has been strongly worked on the central region of Rio Grande do Sul. The project Esperança/Cooesperança is one of the prominent entities regarding to the subject in perspective of the solidarity economy. The case of farming families associated with the Esperança /Cooesperança Project, and their relation to the social economy is the focus of this study, which aims to understand how these families of Santa Maria, develop their productive activities and how they fall in view of the solidarity economy. Their relationship with the production and marketing and their conditions of life are points to be analyzed in this research.
}

Kelly Perlin Cassol*

Carmen Rejane Flores Wizniewsky**

* Mestranda do Programa de Pós-Graduação em Geografia e Geociências pela Universidade Federal de Santa Maria.

** Professora do Departamento de Geociências da Universidade Federal de Santa Maria, RS

Palavras-chave: Agricultura familiar; Cooperação; Economia solidária; Inclusão social.

Key-Words: Family farming; Cooperation; Solidarity economy; Social inclusion. 


\section{Introdução}

Em uma sociedade onde predomina a busca incessante pelo lucro e acúmulo de capital, as questões sociais não encontram muito espaço e as massas de pessoas excluídas social e economicamente só cresce. No Brasil essa massa de excluídos tem suas origens nos mais diversos setores da economia, como é o caso do setor agrário, pois nosso país teve suas bases econômicas sempre ligadas a agricultura. Sabe-se, no entanto que a agricultura comercial, baseada na intensa utilização de insumos agrícolas, como agrotóxicos e mecanização pesada, tem causado a degradação do meio ambiente, a baixa fertilidade e degradação dos solos e acelerado a redução das áreas produtivas. Devido a isto, a busca por novas alternativas para a produção agroecológica, vem cada vez mais sendo valorizada, na busca por um equilíbrio socioambiental. Neste contexto, a agricultura familiar, é uma das principais responsáveis pela produção de alimentos, e vem cada vez mais se inserindo na busca de alternativas que favoreçam sua manutenção, como é o caso da agroecologia e da economia solidária.

Neste contexto, por muito tempo, as organizações ligadas à agricultura familiar, bem como aquelas que atuam no campo da economia solidária, foram relativamente pouco estudadas no que se refere ao seu desenvolvimento organizacional, sem embargo, cada vez mais o governo brasileiro, através do Ministério de Desenvolvimento Agrário, defende a necessidade de fomentar pesquisas e ações que valorizem essas temáticas, através de políticas públicas.

Outro campo de grande importância é o Cooperativismo, este já se faz presente dentro da sociedade há um considerável intervalo de tempo, tendo a sua disposição um bom aparato teórico e regulamentação jurídica. Relacionado a este tema a economia solidária necessita de aprofundamentos teóricos que tratem de seu campo de atuação, tendo em vista sua projeção em escalas tanto nacional quanto internacional e os diversos debates a respeito do sistema de produção capitalista.

O presente artigo trata de uma pesquisa cujo objetivo central é analisar a organização produtiva e os aspectos socioeconômicos dos agricultores familiares associados ao Projeto Esperança/ Cooesperança, de Santa Maria, RS, no âmbito da Economia Solidária.

No que se refere ao aspecto metodológico, a pesquisa tem seu desenvolvimento baseado em um abordagem qualitativa, mais precisamente ao estudo de caso dos agricultores familiares associados ao Projeto Esperança/ Cooesperança do município de Santa Maria, RS, e sua relação com a Economia Solidária, partindo de uma visão geral do fenômeno para um estudo particular do caso em questão, para isso foram aplicados instrumentos qualitativos, com a utilização de entrevistas semi-estruturadas aplicadas a representante do projeto e a cinco agricultores familiares (informantes qualificados) de Santa Maria e sócios da Cooesperança.

A revisão de literatura, realizada visa fornecer o aparato teórico a respeito do tema, e é a base que contém as informações necessárias ao entendimento do assunto, com destaque neste caso para o capitalismo e a agricultura, a agricultura familiar, o cooperativismo e o desenvolvimento agrário e a economia solidária.

Geografia Ensino \& Pesquisa, v. 17, n.1 p. $27-40$, jan./abr. 2013

Projeto Esperançal cooesperança, Santa

Maria, RS: o caso dos agricultores

familiares associados

\section{O Capitalismo e a Agricultura}

A partir do século XI com advento da expansão do comércio, do ressurgimento das cidades e do estabelecimento da burguesia como nova classe social somado a ampliação das áreas destinadas ao plantio para atender a demanda das cidades, faz com que a Europa passe a viver um momento de grande crescimento populacional. Neste contexto se deu a descoberta de técnicas mais apuradas de plantio e o desenvolvimento da indústria de ferramentas. Estes fatos e outros tantos somados contribuíram para que, pôr volta do ano 1500, viesse a surgir um novo sistema de organização político-econômico-social: o capitalismo.

A Revolução Industrial veio a consolidar o capitalismo como forma de produção e também separou a sociedade em dois segmentos ou classes sociais: a burguesia e o proletariado. A bur- 
guesia era constituída por comerciantes enquanto, o proletariado, estava composto pelo conjunto de trabalhadores que necessitavam vender a sua força de trabalho, para obtenção do necessário à sobrevivência.

$\mathrm{Na}$ atualidade muitos fatores envolvidos nos processos do capitalismo mudaram, principalmente em relação a jornada de trabalho, as condições do mesmo e aos direitos dos trabalhadores, porem a divisão da sociedade em classes sociais persistiu e ganhou proporções ainda maiores no que diz respeito a segmentação social. Com o crescente exército de mão-de-obra reserva, ocorre também o aumento do desemprego, o que leva milhares de famílias, todos os anos, a sobreviverem na mais absoluta miséria, descendo cada vez mais na escala social.

Os índices de exclusão social, principalmente nos países subdesenvolvidos, crescem a cada ano, agravados em função das práticas capitalistas, que na busca pelo lucro, não tem o menor comprometimento com o social.

Sob o ponto de vista histórico, a necessidade mais premente desse novo sistema era o suprimento de elementos à indústria-terra, maquinários e mão-de-obra e essas necessidades é que culminaram na mencionada comoditificação, como resultado de uma intervenção deliberada do Estado.

Para Gorender (1994), capitalismo é um modo de produção em que operários assalariados, despossuídos dos meios de produção e juridicamente livres, produzem mais-valia, e em que a força de trabalho se converte em mercadoria, cuja oferta e demanda se processam nas condições da existência de um exército industrial de reserva. A autora destaca ainda que neste modo os bens de produção assumem a forma de capital, de propriedade privada destinada a produção ampliada sob forma de valor, não de valor de uso, mas de valor que se destina ao mercado. Esta definição do capitalismo, do modo de produção capitalista, também é valida para a agricultura, porém, neste caso ela é incompleta, fazendo-se necessário acrescentar mais alguns aspectos típicos, característicos e essenciais. No modo de produção capitalista, a agricultura considerada é um ramo industrial como outro qualquer. Uma peculiaridade existente na agricultura é o problema da terra, uma vez que esta constitui um recurso limitado e insubstituível, porém a propriedade da terra não deve representar empecilho à aplicação de capital na exploração agrícola e sim constitui título a recepção de uma renda fundiária de tipo capitalista.

O desenvolvimento capitalista, segundo Oliveira (1991), é um processo contraditório e desigual, para que seu desenvolvimento seja possível, ele tem que desenvolver aqueles aspectos aparentemente contraditórios. E é por isso que encontramos no Brasil, junto com o processo geral de desenvolvimento capitalista que se caracteriza pela implementação de relações de trabalho assalariadas, a presença de relações de trabalho não capitalistas como, por exemplo, a parceria, 0 trabalho familiar camponês, entre outros.

O desenvolvimento do capitalismo no Brasil está marcado pelo processo desigual que, ao mesmo tempo em que amplia o trabalho assalariado no campo, amplia também o trabalho familiar camponês, abrindo essas, duas formas de produzir no campo espaços distintos de predomínio, o familiar nas pequenas unidades de produção e os assalariados nas grandes unidades capitalistas.

De acordo com Fernandes (1996), é no interior do processo capitalista desigual, que se desenvolveu a exploração econômica, a exclusão cultural e a dominação política, gerando os conflitos e as mais diversas formas de resistência. No interior desse processo formam-se diferentes movimentos sociais que inauguram novas situações e desenvolvem outros processos.

Neste contexto, durante entrevista concedida pela coordenadora do Projeto Esperança/ Cooesperança, Irmã Lourdes Dill, a mesma expõe sua visão em relação ao modelo econômico do mundo atual:

o mundo hoje é regido pelo sistema capitalista, neoliberal e globalizado, ele tem muita desigualdade social, ele dá condições dignas de vida para poucos e a maioria está na exclusão a nível mundial, sem falar no Brasil que é um dos países com mais excluídos da América Latina. (IRMÃ LOURDES DILL - Coordenadora do Projeto Esperança/Cooesperança)

Geografia Ensino \& Pesquisa, v. 17, n.1 p. $27-40$, jan./abr..2013

Cassol, K. P.; Wizniewsky, C. R. F.

ISSN 2236-4994 
É nesta perspectiva que o sistema capitalista de produção se desenvolve, utilizando os mais diversos processos e as mais diversas práticas econômicas, que regem o funcionamento do mundo hoje, trazendo todas as conseqüências já conhecidas, para todos os setores das sociedades.

\section{Agricultura Familiar, uma breve caracterização}

O conceito de agricultura familiar, de acordo com Lamarche (1993) passa por grandes dificuldades em sua demarcação. Para o autor, "a exploração familiar é uma unidade de produção agrícola onde a propriedade e o trabalho, estão intimamente ligados a estrutura familiar". (LAMARCHE, 1993, p.179). Para se compreender o funcionamento da agricultura familiar é preciso, colocar em evidência as diferentes lógicas, em função das quais o agricultor familiar determina suas escolhas fundamentais, destacando principalmente os sistemas de produção, os sistemas fundiários, os sistemas familiares, os sistemas de valores e os de representação.

As especificidades que envolvem agricultura familiar podem ser observadas no modo como esta se reproduz e estabelece suas estratégias, uma vez que esse processo está diretamente ligado ao sistema de valores do explorador.

A agricultura familiar possui sua produção baseada na mão-de-obra familiar, sendo que alguns autores admitem que, ocasionalmente, quando a disponibilidade de mão-de-obra for inferior a necessidade, podem-se admitir trabalhadores assalariados. Ainda nesta linha de pensamento, lembra-se que historicamente as explorações familiares são dotadas de extrema capacidade de adaptação em relação às exigências impostas por situações novas e diversas, às instabilidades climáticas, à coletivização das terras ou a mutação sociocultural determinada pela economia de mercado.

É importante salientar, de acordo com Tedesco (1999) que a propriedade agrícola é definida como uma unidade econômica na qual o produtor rural desenvolve um sistema de produção, tendo em vista a viabilização de uma renda para sua manutenção. Cabe salientar que deve ser entendida como um sistema aberto, o qual troca energia e matéria com o meio, ou seja, recebe influencia do meio, com uma conseqüente adaptação ou mudança, sendo condição básica para a evolução e progresso da propriedade agrícola, o que denota que qualquer alteração no meio provocará mudança na estabilidade econômica e social da propriedade agrícola.

Para Guanziroli et al. (2001), a agricultura familiar, como categoria de análise, não pode ser considerada homogênea, pois possui diferenças econômicas, sociais e culturais. 0 autor ainda aponta três categorias de análise para a agricultura familiar, que indicam diferenciação social e que devem ser consideradas: as capitalizadas, em vias de capitalização e, as descapitalizadas. Destaca ainda que o sistema produtivo que envolve a agricultura familiar é complexo, pois combina várias culturas, criação de animais e transformações primárias, que servem tanto para a subsistência da família quanto para a colocação no mercado.

A escassez de capital prejudica muito o trabalho do agricultor familiar, pois ao ver que aquilo que produz e que sustenta a alimentação dos brasileiros não tem incentivo e, muitas vezes é desvalorizado no mercado, o produtor sente-se desmotivado para buscar novas formas de valorização para seu produto. Além disso, a falta de créditos agrícolas contribui para que o agricultor se descapitalize e acabe vendendo sua propriedade e assim passe a engrossar a população urbana.

Outro fator importante a ser salientado é a relação da agricultura familiar com a natureza, onde

Geografia Ensino \& Pesquisa, v. 17, n.1 p. $27-40$, jan./abr. 2013

Projeto Esperançal cooesperança, Santa

Maria, RS: o caso dos agricultores familiares associados Jean (1994) chama a atenção para a capacidade da agricultura familiar em adaptar-se à produção agroecológica, bem como a uma agricultura sustentável. Em relação à função ambiental da agricultura familiar, pode-se destacar que ela é o tipo de agricultura que possui um dos menores índices de degradação ambiental quando comparada com as demais atividades agrícolas, podendo prover um conjunto de serviços ambientais cujo valor para as gerações presentes e futuras são incalculáveis.

Atualmente pode-se verificar a inserção de atividades pluriativas ou não agrícolas no meio rural promovidas, basicamente, pela agricultura familiar. As atividades não agrícolas exibem uma diversidade de possíveis inserções no mercado como, por exemplo, comércio, prestação de servi- 
ços, turismo, manufaturas, artesanatos, transformações agroindustriais e turismo rural, estas por sua vez, normalmente, se expressam pela trajetória cultural, econômica e social da família rural.

Em relação a economia, a agricultura continua sendo fundamental para o crescimento dos países, contudo as políticas públicas no Brasil não trazem incentivos financeiros para os agricultores familiares, privilegiando sempre os grandes agricultores.

No que tange a sua função social, a agricultura familiar está associada a conceitos de cultura, tradição e identidade. 0 atual fluxo de informações vem transformando rapidamente algumas comunidades de agricultores familiares, nesta perspectiva é interessante que se leve em conta inclusive o impacto das políticas públicas sobre a sociedade nos aspectos culturais e não mais aquele voltado apenas na produção, pois a viabilidade social da agricultura familiar traz um conjunto de fatores sociais como a educação, cultura, lazer, saúde entre outros.

Tendo em vista as diversas formas de contribuição da agricultura familiar para o desenvolvimento da sociedade sob todos os aspectos e a complexidade que envolve o tema, podemos concluir que existe a necessidade de um maior reconhecimento, tanto por parte dos governos quanto da própria sociedade em relação à valorização da agricultura familiar, bem como um maior incentivo ao desenvolvimento das atividades da mesma, pois a agricultura familiar desempenha um papel fundamental dentro da organização de uma sociedade, especialmente em países como o Brasil, onde as relações sociais apresentam um alto grau de exclusão social e requer cada vez mais de alternativas de geração de renda e de inclusão das camadas menos favorecidas à sociedade.

\section{O Cooperativismo}

A cooperação tem origem nos primórdios da humanidade, quando o homem percebeu a necessidade de viver em grupos para caçar, se defender e cultivar, estando sempre associada às lutas pela sobrevivência, e posteriormente às mudanças e crises econômicas, essa corrente pode ser observada na organização social de diversos povos antigos, como os babilônios, gregos, egípcios, astecas, maias e incas. Com o advento da industrialização, ela organizou-se de modo a buscar alternativas para enfrentar as condições precárias de trabalho decorrentes do sistema econômico capitalista de livre concorrência, e atualmente busca o desenvolvimento econômico e social através de grupos estruturados e visando minimizar as altas taxas de exclusão social e desemprego que assombram nossa sociedade, em função da estrutura conjuntural do sistema capitalista vigente.

Cooperativismo, de acordo com Brezolin (1988), consiste na filosofia da busca do social através do econômico, com o objetivo de resolver os interesses comuns com base na participação efetiva dos indivíduos que integram esse processo. Estes indivíduos, os cooperativados, são os verdadeiros responsáveis pela sustentação teórica e prática do cooperativismo.

A cooperativa é uma sociedade de pessoas, organizadas em bases essencialmente democráticas, que visam não só o suprimento de necessidades, impostas pelo mercado, como bens e serviços, mas também, buscar realizar determinados programas educativos e sociais que sejam formadores para a cooperativa e para a sociedade.

As características específicas da empresa cooperativa (propriedade, gestão e repartição cooperativas) determinam que a mesma possa ser concebida como parte integral ou extensão das empresas individuais de seus associados.

Em alguns casos o cooperativismo passa a ser uma alternativa, principalmente aquele voltado a atender ou representar a pequena produção, visando a solução para inúmeros problemas inerentes a escala de produção capitalista, verificada no atual sistema econômico.

Nos dias atuais o cooperativismo possui uma grande expressividade dentro dos ramos econômico e social e tem sido com freqüência, objeto de estudo e atenção de vários autores ao longo de sua trajetória. Assim, Pedó (2007, p.90) destaca:

Geografia Ensino \& Pesquisa, v. 17, n.1 p. $27-40$, jan./abr..2013

Cassol, K. P.; Wizniewsky, C. R. F. 
Acredito que o cooperativismo surge em momentos de crise a exemplo da primeira revolução industrial, amparada pela doutrina do liberalismo clássico e, na atualidade, por nova crise advinda da terceira revolução industrial e da revitalização do capitalismo financeiro globalizado. Em especial na década de 90 , ressurge como uma possibilidade de inclusão dos segmentos mais vulnerabilizados e, novamente, 0 interesse pela doutrina cooperativa é despertado.

O cooperativismo no Brasil, para Rios (1989, p.52) "surge como uma promoção das elites (econômicas e políticas) numa economia predominantemente agro-exportadora". Não se trata de um movimento vindo de baixo, como foi o caso europeu, mas sim imposto de cima, descaracterizando um movimento social de conquista e enfatizando uma política de controle social e de intervenção estatal. Aqui o cooperativismo localiza-se principalmente no meio rural, opondo-se mais uma vez ao movimento cooperativista europeu, que teve sua maior expressão urbana.

Pedó (2007) em sua tese de doutorado destaca que primeira referência legislativa com relação ao movimento cooperativista se deu pelos Decretos n. 796 e n. 869, ambos de 1890, que autorizam a organização das sociedades cooperativas. Já em 1903 é criado o primeiro dispositivo legal, com o Decreto n. 979, que trata especificamente das atividades cooperativas. Em 1932, com o Decreto n. 22.239, realmente surgiu uma legislação a respeito das cooperativas, o Decreto foi considerado como a primeira Lei Rochdaleana, uma vez que consagrava vários princípios de Rochdale no país.

A constituição de 1988 assegura o início de uma nova fase pela qual se submetem as sociedades cooperativas, com o advento regulamentação da não intervenção estatal na criação e funcionamento das sociedades cooperativas.

O cooperativismo brasileiro, segundo Pedó (2007), vem sofrendo fortes mudanças devido a fatos políticos, culturais, jurídicos e socioeconômicos, além de transformações que causam impactos estruturais em razão das transformações ocorridas no cenário mundial, especialmente no início do século XXI. Pode-se citar mudanças estruturais no Brasil, como por exemplo, o desconhecimento da Organização das Cooperativas Brasileiras (OCB), como órgão técnico do governo-consultivo e representante do sistema de cooperativismo brasileiro tanto pelas cooperativas das chamadas vertentes sindicais quanto as de economia solidária.

"As características básicas da organização cooperativa são a igualdade de direitos dos associados, a solidariedade e a gestão participativa." (ZANLUCA, 2011, p.159). No entanto, o autor destaca que a distribuição de tarefas introduz elementos de hierarquização entre os associados. No Brasil há inúmeros casos de setores que passaram a atuar por conta própria, aliados em torno dos ideais cooperativistas.

Muitas pessoas podem não perceber, mas no dia-a-dia usam serviços e produtos que têm como origem as cooperativas. Num país como o Brasil, carente de empregos, que precisa crescer a uma média alta para permitir a colocação e a recolocação de profissionais no mercado de trabalho, estimular o cooperativismo deveria ser uma grande opção para acelerar o desenvolvimento.

\section{Economia Solidária, algumas considerações}

Geografia Ensino \& Pesquisa, v. 17, n.1 p. 27-40, jan./abr. 2013

Projeto Esperançal cooesperança, Santa

Maria, RS: o caso dos agricultores familiares associados

Com a supremacia do sistema capitalista de produção e suas práticas neoliberais, ocorre exclusão de grande número de trabalhadores do mercado, o que requer o surgimento de formas alternativas de economia, como um novo cooperativismo, muito mais próximo de suas origens históricas. Novas formas institucionais de autogestão são criadas e passam a ser conhecidas como "Economia Solidária". A Economia Solidária surge como uma das alternativas à pobreza e à questão de exclusão social. Ainda que as pesquisas na área não sejam vultosas, já é possível conceituar esse novo campo de conhecimento, ainda que na literatura, o tema não esteja sendo totalmente contemplado e nem mesmo haja um consenso dentre os autores a respeito do tema.

No âmbito do Sistema Nacional de Informação em Economia Solidária-SIES (SIES, 2006, p.2): 
A Economia Solidária é compreendida como o conjunto de atividades econômicas de produção, distribuição, consumo, poupança e crédito, organizadas e realizadas solidariamente por trabalhadores e trabalhadoras sob a forma coletiva e autogestionária. Nesse conjunto de atividades e formas de organização destacam-se, segundo o SIES, quatro importantes características: cooperação, autogestão, viabilidade econômica e solidariedade.

Além disso, a Economia Solidária possui uma finalidade multidimensional, isto é, envolve a dimensão social, econômica, política, ecológica e cultural. Isto porque, além da visão econômica de geração de trabalho e renda, as experiências de Economia Solidária se projetam no espaço público, no qual estão inseridas, tendo como perspectiva a construção de um ambiente socialmente justo e sustentável. Vale ressaltar ainda que a Economia Solidária não se confunde com o chamado "terceiro setor" que substitui o Estado nas suas obrigações legais e inibe a emancipação de trabalhadoras e trabalhadores, enquanto sujeitos protagonistas de direitos. A Economia Solidária reafirma, assim, a emergência de atores sociais, ou seja, a emancipação de trabalhadoras e trabalhadores como sujeitos históricos.

Singer (1999) entende a economia solidária como um conjunto de experiências coletivas de trabalho. Eid e Pimentel $(2000$, p.3) destacam ainda que a economia solidária é um conjunto de:

\begin{abstract}
Experiências coletivas de trabalho, de produção, de comercialização e de crédito, organizadas por princípios solidários, que se apresentam sob diversas formas: cooperativas, associações de produtores, empresas autogestionárias, bancos comunitários, clubes de trocas, bancos do povo e diversas organizações populares urbanas e rurais. Desenvolvem principalmente atividades econômicas como: plantio, beneficiamento e comercialização de produtos primários, prestação de serviços, confecções, alimentos, artesanatos, entre outras.
\end{abstract}

Ainda sob o ponto de vista econômico, a economia solidária não é uma ideologia, mas uma saída possível, uma esperança de desafogo para a atual situação de exclusão social e crise.

No Brasil, o crescimento da Economia Solidária, está cada vez mais se orientando rumo a uma articulação nacional, configurando redes locais e uma plataforma comum. Um salto considerável se dá a partir das várias edições do Fórum Social Mundial, espaço privilegiado onde diferentes atores, entidades, iniciativas e empreendimentos puderam construir uma integração. Em 2003, foi criada a Secretaria Nacional de Economia Solidária (SENAES) junto ao Ministério do Trabalho e Emprego, que atua como a entidade que propõe, organiza e implementa políticas de apoio à economia solidária. Simultaneamente à criação desta Secretaria, foram criados, o Conselho Nacional de Economia Solidária (CNES) e o Fórum Brasileiro de Economia Solidária (FBES), que congrega a grande maioria dos movimentos sociais, constituído em uma agência de fomento e de assessoria de economia solidária no Brasil. O FBES estrutura-se de forma a garantir a articulação entre três segmentos do movimento de Economia Solidária, que são os empreendimentos solidários, as entidades de assessoria e fomento, e os gestores públicos.

Os empreendimentos solidários abrangem as diversas formas concretas de manifestação na Economia Solidária, que são de uma riqueza e diversidade consideráveis. Os empreendimentos solidários são os principais protagonistas e público-alvo do FBES, compondo a maioria da representação em todas as instâncias decisórias do mesmo. Como exemplos de empreendimentos solidários temos: cooperativas, associações populares e grupos informais (de produção, de serviços, de consumo, de comercialização e de crédito solidário, nos âmbitos rural e urbano); empresas recuperadas de autogestão (antigas empresas capitalistas falidas recuperadas pelos/as trabalhadores/as); agricultores familiares; fundos solidários e rotativos de crédito (organizados sob diversas formas jurídicas e também informalmente); clubes e grupos de trocas solidárias (com ou sem o uso de moeda social, ou moeda comunitária); redes e articulações de comercialização e de cadeias produtivas solidárias; lojas de comércio justo; agências de turismo solidário; entre outras.

O terceiro segmento do movimento é o de gestores públicos, composto por representantes de governos municipais e estaduais que tenham em sua gestão programas explicitamente voltados à Economia Solidária. Este segmento se faz representar nacionalmente por uma rede de gestores públicos, que tem cadeira na Coordenação Nacional do FBES como uma das entidades/redes nacionais.

Geografia Ensino \& Pesquisa, v. 17, n.1 p. $27-40$, jan./abr..2013

Cassol, K. P.; Wizniewsky, C. R. F.

ISSN 2236-4994 33 


\section{O Projeto Esperança/Cooesperança, no município de Santa Maria e Região Central do Rio Grande do Sul}

O Projeto Esperança é um dos Setores do Banco da Esperança da Diocese de Santa Maria, integrado com a Cáritas Regional, RS (Confederação Humanitária da Igreja Católica). A ideia inicial do projeto surgiu do estudo do livro: "A Pobreza e a Riqueza Dos Povos" do autor africano Albert Tévoèdjeré. Tal estudo iniciou em 1982 e, em 1985 foram criados os primeiros Projetos Alternativos Comunitários (PACs). O Projeto Esperança foi criado em 15 de agosto de 1987, com o objetivo de proporcionar a articulação e congregação de experiências de Economia Popular Solidária (EPS), no meio urbano e rural e na prestação de serviços autogestionários na região central do estado.

O Projeto Esperança vem construindo o associativismo, o trabalho, a solidariedade, a cidadania, um novo modelo de cooperativismo autogestionário, a economia popular solidária e a inclusão social, através de alternativas concretas de radicalização da democracia, do desenvolvimento humano solidário e sustentável e a "reinvenção da economia", que coloca o trabalho acima do capital, formando sujeitos para o pleno exercício da cidadania e inclusão social, com dignidade e trabalho.

A Cooesperança é a Cooperativa Mista de Pequenos Produtores Rurais e Urbanos vinculados ao Projeto Esperança. É uma central que congrega e articula os grupos organizados da região central do estado do Rio Grande do Sul e viabiliza a comercialização direta dos produtos originários dos empreendimentos solidários do campo na cidade e que fortalecem juntos, com todos os grupos, um novo modelo de cooperativismo.

A cooperativa foi fundada em 29 de setembro de 1989, e tem trabalhado desde então juntamente com o Projeto Esperança na busca da articulação dos empreendimentos solidários da região central do Rio Grande do Sul, dentro de uma proposta alternativa, solidária, transformadora, autogestionária e do desenvolvimento sustentável.

Os principais eixos que o Projeto Esperança/Cooesperança e a Teia Esperança trabalham atualmente são: a organização, a formação, a agroindústria familiar, a agricultura familiar agroecológica, o trabalho dos catadores (as), o artesanato e confecção, a economia popular solidária, a comercialização direta, a reforma agrária, o consumo justo, ético e solidário, o tabaco zero, o resgate das sementes crioulas, as políticas públicas, sempre com a certeza de que "outro mundo é possível".

Segundo a coordenadora do projeto, Irmã Lourdes Dill, em entrevista concedida para realização deste trabalho, o número de associados ao Projeto Esperança/Cooesperança, que congrega 30 municípios, possui em torno de 4.500 famílias associadas, em 230 grupos e que somam mais de 20 mil pessoas formando um público muito grande nas diferentes áreas.

Um dos eixos de destaque do projeto consiste na Agricultura Familiar Agroecológica, que trabalha junto aos agricultores familiares associados, formas alternativas de produção, enfatizando técnicas de plantio e manejo sustentáveis. Produzir produtos orgânicos e de boa qualidade é um dos principais objetivos deste eixo da cooperativa, onde os grupos associados são os responsáveis por todo o processo de produção contando sempre com o auxílio do projeto, que atua na parte da formação agroecológica em parceria com outras entidades ligadas ao tema.

A agricultura familiar e a agroecologia são pontos de grande atuação do projeto desde sua criação. A agroecologia é trabalhada como processo de transição, investindo especialmente na conscientização dos agricultores e consumidores. 0 trabalho desenvolvido junto aos agricultores familiares associados ao projeto se dá de forma a estabelecer processos educativos na perspectiva de alcançar a conscientização e a motivação para o exercício da agricultura agroecológica, apostando que a agricultura familiar é o caminho para erradicar a fome e a miséria no Brasil.

São mais de 40 espaços fixos de comercialização direta dos diversos grupos nos municípios da região. Sendo que o ponto de articulação e integração da Teia Esperança é o Terminal de Comercialização Direta, hoje denominado Centro de Referência de Economia Solidária Dom Ivo Lorscheiter, localizado no município de Santa Maria, RS, onde se dão as trocas de experiências e de produtos, todos os sábados no Feirão Colonial Semanal. 
Nos pontos de comercialização da Teia Esperança são comercializados diversos produtos, entre eles produtos coloniais, hortigranjeiros ecológicos, caseiros, artesanais, de panificação, de confecção, de serigrafia, artesanato, produtos de agroindústria familiar e carnes, prestação de serviços, com a proposta da economia solidária, na perspectiva de gerar trabalho, renda e inclusão social.

Cabe salientar que na organização da cooperativa são arrecadados $5 \%$ dos lucros dos associados para a manutenção e a para a realização de melhorias na própria cooperativa.

O Projeto Esperança/Cooesperança é um dos maiores projetos do país em relação ao desenvolvimento da economia solidária como um meio eficiente de inclusão social, valorizando 0 comércio justo, ético e solidário, a agricultura familiar e a produção ecológica. Ainda é uma entidade atuante, em todas as escalas, na organização e articulação dos movimentos referentes à economia solidária, sendo a principal responsável pela Feira Internacional de Economia Solidária, caracterizada por ser um dos maiores eventos da América Latina na área, além de atuar na criação das políticas públicas referentes ao setor. Sendo assim o projeto representa um grande avanço da economia solidária e uma importante entidade dentro do município de Santa Maria, RS.

Em relação às políticas públicas na área da economia solidária a representante do projeto diz que o mesmo faz parte das políticas públicas, uma vez que uma verdadeira política pública não nasce só do governo, mas também com a sociedade. Destaca que as políticas públicas em nível de agricultura como o Programa Nacional de Fortalecimento da Agricultura Familiar (PRONAF) surgiram com a participação popular e atualmente está fortalecendo programas nacionais de economia solidária dentro da Secretaria Nacional de Economia Solidária (SENAES). E a rede que forma toda essa articulação entre os empreendimentos do Brasil tem hoje aproximadamente 22 mil empreendimentos de economia solidária, que entre eles possuem mais de 1,5 milhão de trabalhadores que estão inseridos nestes empreendimentos, que movimenta mais ou menos 6 bilhões de reais, atualmente. Destaca ainda que esta surgindo uma política pública de crédito e de formação, enfatizando que são políticas recentes e que o objetivo para o futuro é a criação de um ministério de economia solidária.

\section{O caso dos agricultores familiares associados ao Projeto Esperança/Cooesperança e sua relação com a economia solidária}

Em julho de 2011, durante a $7^{a}$ Edição da Feira do Mercosul e $18^{a}$ Feira Estadual do Cooperativismo Alternativo, realizada no município de Santa Maria, RS, foram realizadas as entrevistas que deram origem a este trabalho. $O$ referido evento conta com a participação de 435 municípios, de 27 Estados do Brasil e 15 países (América Latina, Europa e África). Os cinco produtores selecionados para entrevista são de municípios próximos a Santa Maria, RS. A escolha dos mesmos se fez em razão destes participarem do Projeto Esperança/Cooesperança no município, além de participar todos os sábados do feirão semanal no Centro de Referência de Economia Solidária Dom Ivo Lorscheiter, também localizado em Santa Maria, RS, onde comercializam grande parte de sua produção.

As entrevistas realizadas com os produtores participantes do projeto Esperança/Cooesperança visam compreender a necessidade dos mesmos na busca por alternativas para um desenvolvimento urbano e rural sustentável, para a construção de uma sociedade justa, economicamente viável, ambientalmente sadia, organizadamente cooperativada e politicamente democrática. Dentre as questões que nortearam as entrevistas busca-se também verificar o que levou os agricultores a se aproximar de uma associação ou cooperativa, e quais vantagens os mesmos vêem nessa forma de organização.

De uma forma geral, durante as entrevistas, pode-se observar que todos os agricultores entrevistados, buscam se associar a uma cooperativa principalmente pelo fato de melhorar suas vendas, e consequentemente sua renda. A aproximação com a Cooesperança se dá também devido a busca de mercado diferenciado para a comercialização dos produtos, uma vez que um dos objetivos do projeto Esperança/Cooesperança é a articulação dos produtores e consumidores para

Geografia Ensino \& Pesquisa, v. 17, n.1 p. 27-40, jan./abr..2013

Cassol, K. P.; Wizniewsky, C. R. F.

ISSN 2236-4994 35 
motivar o comércio justo e o consumo ético e solidário através de pontos de comercialização direta dos municípios da região centro do estado do Rio Grande do Sul.

Grande parte da produção proveniente da agricultura familiar é comercializada no feirão semanal do Centro de Referência de Economia Solidária Dom Ivo Lorscheiter, e o restante, cada grupo ou cada família separadamente, escolhe a forma e o local de venda adequado a sua necessidade. Os pontos de venda de parte da produção estão localizados nos demais pontos da Teia Esperança, em pontos fora da economia solidária ou nas propriedades dos agricultores, conforme a escolha dos agricultores ou do grupo.

A agricultura familiar é um importante ramo no âmbito da economia solidária, como uma alternativa de inclusão social e de manutenção de famílias no campo, evitando assim as diversas consequências do êxodo rural. Dentro da Cooesperança, a agricultura familiar agroecológica é um dos setores de destaque, possuindo centenas de famílias associadas e organizadas em grupos de trabalho que hoje estão inseridas no mercado produtivo através do trabalho solidário junto a cooperativa, desenvolvendo todo o processo produtivo, desde a produção propriamente dita até a comercialização de seus produtos nos pontos de comercialização do projeto.

A produção comercializada é cultivada pela maioria de forma orgânica, ou fazendo o menor uso possível de agrotóxicos e insumos químicos. Outro ponto de grande importância é a preocupação demonstrada pelos entrevistados em relação a sustentabilidade da produção, onde todos demonstraram que se preocupam em utilizar técnicas de plantio que não agridam o meio ambiente visando a preservação do mesmo. Os principais produtos produzidos e comercializados pelos agricultores familiares entrevistados são hortigranjeiros, frutas, produtos agroindustriais, principalmente derivados do leite, como por exemplo, queijo e doce de leite, derivados da cana-de-açúcar, como melado, açúcar mascavo e rapaduras, além de geléias e ovos.

A aceitação dos produtos na opinião dos agricultores é muito grande, pois os consumidores da economia solidária procuram os produtos pela qualidade, na forma de produção e preparo. A forma de produção orgânica, que proporciona um melhor sabor aos produtos e não causa danos à saúde, demonstra uma qualidade superior dos produtos comercializados na cooperativa, em relação aos produtos comercializados no mercado convencional. A garantia na oferta de produtos frescos, de qualidade e sem o uso abusivo de produtos químicos, usando apenas os produtos necessários para realizar a correção do solo e garantir a produção, é determinante na qualificação destes produtos. A produção orgânica, de acordo com Schimaichel e Resende (2007, p.2) se enquadra no que se entende por modelo de produção alternativo de alimentos e insumos:

\footnotetext{
O sistema de produção orgânico é considerado uma forma de manejo sustentável do meio ambiente, devido a suas práticas levar em consideração a promoção da qualidade ambiental, a não utilização de compostos sintéticos (agrotóxicos e fertilizantes), componentes que causam desequilíbrios e são agressivos ao meio ambiente. Os produtores orgânicos ocupam uma posição de crescimento dentro do quadro da produção mundial de alimentos e seus produtos são extremamente procurados, devido à conscientização dos consumidores nas últimas décadas. Obviamente, quando se considera o setor produtivo como um todo, os produtores orgânicos são considerados uma minoria ainda pouco significativa no contexto do agronegócio.
}

Geografia Ensino \& Pesquisa, v. 17, n.1 p. $27-40$, jan./abr. 2013

Projeto Esperançal cooesperança, Santa

Maria, RS: o caso dos agricultores familiares associados
A não dependência ou a diminuição da dependência de insumos externos de acordo com Schimaichel e Resende (2007), aliados à melhoria da qualidade do solo gerada pelas práticas orgânicas, qualifica a agricultura orgânica como sustentável, dando ao pequeno produtor condições de produzir a um custo menor. Essa diminuição do impacto ambiental e da despesa do produtor, para Darolt (2002) é capaz de proporcionar melhoria na renda familiar e conseqüentemente na qualidade de vida do agricultor.

Os agricultores associados a Cooesperança vêem o significado de cooperativa de diferentes formas, para alguns ela é sinônimo de democracia e união de pessoas, o que vem de encontro com o que descreve Teixeira e Zanluca (2005, p.159), onde estes destacam que "cooperativa é uma associação de pessoas com interesses comuns, economicamente organizada de forma de- 
mocrática, e contan?do com a participação livre de todos, prestando serviços sem fins lucrativos". Porém, alguns associados entrevistados acreditam que ultimamente não é o que esta ocorrendo na cooperativa da qual participam, pois existem interesses diversos dentro da mesma e apenas alguns são privilegiados, mas de uma forma geral o projeto Esperança/Cooesperança está conseguindo ajudar muitos produtores a ter mais sucesso em suas vendas, principalmente na venda de produtos orgânicos e, outro ponto a ser destacado é que o projeto está unindo os produtores cada vez mais.

Quanto ao significado das mudanças na qualidade de vida dos agricultores associados e suas famílias após o ingresso na economia solidária, as respostas foram positivas em relação a meIhorias na qualidade de vida das famílias associadas, como exemplos, temos, aumento de convívio social, devido a encontros e reuniões realizadas, aumento da produção, facilidade de venda dos produtos, aumento da renda mensal, lazer, segurança, alternativas de produção, maior aceitação dos produtos e a conquista de novas amizades, estas são as principais melhorias citadas. Um ponto que merece destaque é a valorização do conhecimento por parte dos agricultores associados ao projeto, pois estes demonstram interesse em aprofundar seus conhecimentos e valorizam muito as reuniões dos associados do grupo para a realização dos estudos referentes às formas de produção ecológicas e demais assuntos.

Ao serem questionados sobre ter filhos, e a possibilidade destes continuarem no meio rural, os entrevistados, foram unanimes em afirmar que incentivam seus filhos a estudar e buscar alternativas de trabalho que não estejam ligadas a vida no campo. Este fato se deve muitas vezes, a falta de incentivos às atividades no meio rural, a desvalorização dos produtos, entre outros fatores. O PRONAF (Programa Nacional de Fortalecimento da Agricultura Familiar) apresenta uma linha de crédito destinada aos jovens rurais, porém está medida não é suficiente para manter grande parte dos jovens no meio rural, e ainda de acordo com Castro $(2009$, p. 6) "a juventude rural não se apresenta como foco prioritário para as políticas públicas de juventude". Isto leva, então, muitos filhos de agricultores a buscar uma nova vida no meio urbano, escolha esta, que está fundamentada em distintas razões, entre as quais, de acordo com Brumer e Spanevello (2008), podemos citar a penosidade do trabalho agrícola e a questão de renda. A questão da renda é, segundo os entrevistados, o fator de maior relevância, uma vez que a renda no meio rural sofre muitas variações de acordo com mercado e também com as mudanças climáticas.

Quando indagados sobre os problemas enfrentados antes do ingresso na economia solidária, os agricultores argumentaram que os principais problemas eram o preço baixo de seus produtos no mercado convencional e o isolamento social das famílias, que ficavam muito tempo trabalhando em suas propriedades sem terem convívio com outras pessoas. Atualmente, os entrevistados destacam que os maiores problemas que tem enfrentado são os problemas climáticos, como por exemplo, as fortes geadas e secas prolongadas. $O$ fato de não fazer uso de agroquímicos também tem consequências na produção, pois as plantas são muito vulneráveis a ataques de insetos e pragas, e muitas vezes há grandes perdas na produção. Um ponto de extrema importância destacado pelos entrevistados é o uso indevido do 'selo orgânico', pois muitos utilizam agrotóxicos na produção e comercializam seus produtos como orgânicos juntamente com o restante dos produtores da feira. A falta de assistência técnica também é visto como uma deficiência pelos agricultores entrevistados.

Por fim, quando questionados sobre as perspectivas futuras os agricultores que participam do projeto Esperança/Cooesperança afirmam ter o desejo de diversificar e ampliar a produção de alimentos orgânicos, objetivando assim uma maior renda e melhor qualidade de vida. Um ponto de destaque entre as perspectivas futuras é o desejo de parar com o plantio de fumo e arroz. 0 desejo de parar com o plantio de fumo e arroz está associado ao seu elevado custo de produção e baixo preço na comercialização, além disso, as duas culturas fazem uso de grande quantidade de agrotóxicos, o que dentre outros danos leva a autocontaminação dos produtores, acarretando assim muitos problemas de saúde. Aqui nota-se novamente a preocupação com o meio ambiente e com a qualidade de vida dos próprios agricultores e também dos consumidores.

Geografia Ensino \& Pesquisa, v. 17, n.1 p. $27-40$, jan./abr..2013

Cassol, K. P.; Wizniewsky, C. R. F. 


\section{Considerações Finais}

$\mathrm{Na}$ tentativa de superar os problemas deixados pela modernização da agricultura e garantir a produção de alimentos de maneira sustentável, surge a agricultura sustentável que se refere a busca de rendimentos duráveis em longo prazo, por meio do uso de tecnologias de manejo ecologicamente adequadas, e onde se trabalha a diminuição da dependência dos agricultores por insumos industriais, o que, por sua vez, afeta os interesses do capital. Outra tentativa de superação dos entraves deixados pela modernização são as práticas agroecológicas que se situam como novos segmentos produtivos e colocam lado a lado produtores rurais, pesquisadores e extensionistas e, sobretudo, consumidores, todos com o firme propósito de construir uma agricultura mais justa, ecologicamente correta, sustentável, que respeite o meio ambiente e valorize o trabalho humano, que seja saudável e que valorize o conhecimento local, o comércio como relação humana, preservando a vida e a interação social.

Neste contexto, portanto, surge a proposta do Projeto Esperança/Cooesperança no município de Santa Maria, RS, que luta por uma economia popular solidária, pela defesa do meio ambiente, pela agroecologia, dentre outros objetivos, colocando sempre a vida em primeiro lugar com igual participação entre homens e mulheres comprometidos com o fortalecimento da agricultura familiar e com um consumo justo, ético e solidário, trabalhando em parcerias e ajudando a construir políticas públicas que auxiliam na construção da sociedade, no desenvolvimento urbano, rural e regional sustentável.

Como resultado desta pesquisa obteve-se informações sobre as formas de produção e comercialização da agricultura familiar no âmbito da economia solidária, vale destacar os impactos positivos que a economia solidária proporcionou na vida das famílias de agricultores associados ao Projeto Esperança/Cooesperança, com destaque para o aumento de convívio social, os estudos realizados, os encontros e as reuniões realizadas, o aumento da produção, a facilidade de venda dos produtos, o aumento da renda mensal, as alternativas de produção, a maior aceitação dos produtos e a conquista de novas amizades são os principais pontos valorizados pelos agricultores familiares associados à cooperativa. Outro ponto de grande importância é a relação mantida entre os associados com a forma de produção e consumo solidário, onde ocorre uma transformação na forma de pensar das pessoas envolvidas, passando gradativamente do individualismo para as formas coletivas de organização. Este novo setor do conhecimento é caracterizado por ser uma nova forma de produção desatrelada ao mercado convencional, onde a busca pela inclusão social é seu maior objetivo, esta forma de produção visa fornecer alternativas ao desemprego, busca formas de produção sustentáveis, autogestionárias e solidárias.

Os resultados da pesquisa apontam que outra realidade é possível frente ao desemprego e a exclusão social que assola as sociedades modernas principalmente em países subdesenvolvidos como é o caso do Brasil. E, por fim, pode - se inferir, que frente a todas as implicações deixadas pela modernização da agricultura uma das propostas mais avançadas para superar os diversos entraves deixados pela modernização é a valorização da agricultura familiar e de seu potencial. Outra proposta é a valorização da agroecologia, como forma de produção agrícola voltada para a produção sustentável, onde se incorporam os conhecimentos tradicionais e técnicos dos agricultores, valorizando o meio ambiente e uma comercialização solidária reforçando assim as relações tanto dos agricultores entre si e destes para os consumidores, caracterizando assim novas relações de mercado.

Geografia Ensino \& Pesquisa, v. 17, n.1 p. $27-40$, jan./abr. 2013

Projeto Esperançal cooesperança, Santa Maria, RS: o caso dos agricultores

familiares associados 
ABRAMOVAY, R. Paradigmas do capitalismo em questão. São Paulo: Editora da Unicamp, 1992.

BRASIL. Constituição da Republica Federativa do Brasil de 1988. Disponível em <http:// www.planalto.gov.br/ccivil_03/Constituicao/Constit ui\%C3\%A7ao.htm>. Acesso em 16 de novembro de 2011.

BRASIL. Ministério do Trabalho e Emprego. Secretaria Nacional da Economia Solidária. Sistema Nacional de Informação em Economia Solidária-SIES. Guia de Orientações e Procedimentos do SIES. Brasília, 2006. Disponível em <http://www.mte.gov.br/empregador/economiasolidaria/ conteudo/GOPS_revisto.pdf>. Acesso em 12 de novembro de 2011.

BRASIL. Decreto n. 979, de 6 de Janeiro de 1903. Disponível em <http://www.planalto.gov.br/ ccivil_03/decreto/antigos/D0979.htm>. Acesso em 12 de novembro de 2011.

BRASIL. Decreto n. 22.239, de 19 de Dezembro de 1932. Disponível em <http://www.ocb. org.br/site/cooperativismo/arquivos/decreto22239_1932.pdf>. Acesso em 12 de novembro de 2011.

BREZOLIN, T; Introdução ao Cooperativismo. Universidade Federal de Santa Maria. Cadernos do CCSH. Rio Grande do Sul, 1988.

BRUMER, A.; SPANEVELLO, R. M. Jovens agricultores da Região Sul do Brasil. Porto Alegre: UFRGS; Chapecó: Fetraf-Sul/CUT, 2008. Relatório de Pesquisa.

CASTRO, E. G. Juventude Rural no Brasil: processos de exclusão e a construção de um ator político. Revista Latinoamericana de ciencias sociales, niñez y juventud, 2009. v. 7, p. 179-208.

CRUZ, A. As condições históricas do aparecimento da "economia solidária" no Brasil: as tendências estruturais do mercado de trabalho. Disponível em: <http//www.pfilosofia.pop.com.br>. Acesso em: 10 setembro 2011.

DAROLT, M. R. Agricultura Orgânica: inventando o futuro. Londrina: IAPAR, 2002.

EID, F. \& PIMENTEL, A. Economia Solidária: desafios do cooperativismo de reforma agrária no Brasil. Disponível em <http://www.unitrabalho.org.br/ IMG/pdf/e-solidaria_desafios-do cooperativismo.pdf>. Acesso em 16 de novembro de 2011.

FAO/INCRA. Diretrizes de política agrária e desenvolvimento sustentável. Brasília, 1995.

GUANZIROLI, C. ROMEIRO, A. BUAINAIN, A. DISABATTO, A. BITTENCOURT, G. Agricultura familiar e reforma agrária no século XXI. Rio de Janeiro: Garamond, 2001.

JEAN, B. A forma social da agricultura familiar: sobrevivência ou criação de uma economia moderna. Cadernos de Sociologia. Porto Alegre: PPGS/UFRGS, v. 6, 1994.

LAMARCHE, H. A Agricultura familiar: comparação internacional - uma realidade multiforme. (trad. De TIJIWA, A.) Coleção Repertórios. Campinas: Ed. UNICAMP, 1993.

Geografia Ensino \& Pesquisa, v. 17, n.1 p. $27-40$, jan./abr.. 2013

PEDÓ, J. C. J. Economia Solidária: rumos de uma alternativa às transformações do mundo do trabalho e da questão social. 2003. Dissertação de Mestrado. Pontifícia Universidade Católica do Rio Grande do Sul, Porto Alegre. 
PEDÓ, J. C. J. O cooperativismo na perspectiva da economia solidária: evidências locais a partir da COOPAL. 2007. Tese de Doutorado Universidade Federal de Pelotas, Pelotas.

RIOS, G. S. L. O que é cooperativismo. $2^{\circ}$ Ed. São Paulo: Brasiliense, 1989.

SINGER, P. Uma Utopia Militante: repensando o socialismo. 2. Ed. Petrópolis: Vozes, 1998.

SHIMAICHEL, G. L. \& RESENDE, J.T.V. A importância da certificação de produtos orgânicos no mercado internacional. Disponível em:<web03.unicentro.br/especialização/revista_ pos/paginas/2\%20edicao/agrárias/pdf/1-ed2-CA - importa.pdf>. Acesso em 30 de outubro de 2011.

TEDESCO, J. C. Agricultura familiar: realidades e perspectivas. $2^{\mathrm{a}}$ Ed. Passo Fundo: Ed. EDIUPF, 1999.

TEIXEIRA, P. H., ZANLUCA, J. C. Imposto de Renda das Empresas: Com Ênfase em Planejamento Tributário. $1^{\mathrm{a}}$ Ed. Curitiba: Portal Tributário, 2005.

ZANLUCA, J.C. Manual de Sociedades Cooperativas. Disponível em: <http://www.portaltributario.com.br/obras/cooperativas.html>. Acesso em 30 de outubro de 2011.

\section{Correspondência:}

Kelly Perlin Cassol- Rua Luiz Soldera, 118, Santo Antônio. Faxinal do Soturno, RS. CEP: 97220-000

E-mail: perlinkelly@gmail.com

Recebido em 22 de março de 2012.

Revisado pelo autor em 20 de outubro de 2012.

Aceito para publicação em 19 de novembro de 2012. 